\title{
Coating of Transparent Ti-containing Mesoporous Silica Thin Films on Quartz and Aluminum Alloy Substrates for Fabrication of Highly Hydrophilic Surfaces
}

\author{
Yu HORIUCHI, ${ }^{1)}$ Haruhisa URA, ${ }^{1)}$ Hye-jin YOO, ${ }^{2)}$ Takashi KAMEGAWA, ${ }^{1)}$ Kohsuke MORI, ${ }^{11}$ \\ Norikazu NISHIYAMA ${ }^{3)}$ and Hiromi YAMASHITA ${ }^{11}$
}

1) Division of Materials and Manufacturing Science, Graduate School of Engineering, Osaka University, 2-1, Yamada-oka, Suita, Osaka 565-0871 Japan. E-mail: yamashita@mat.eng.osaka-u.ac.jp

2) Surface Technology Research Group, POSCO Technical Research Laboratories, 699, Gumho-dong, Gwangyang, Jeonnam 545-090, Korea. $\quad 3)$ Department of Materials Engineering Science, Graduate School of Engineering Science, Osaka University, 1-3, Machikaneyama-cho, Toyonaka, Osaka 560-8531 Japan.

(Received on July 6, 2009; accepted on November 11, 2009)

\begin{abstract}
The fabrication of transparent Ti-containing mesoporous silica thin films (Ti-MSTFs) showing highly hydrophilic properties was achieved on quartz and Al alloy substrates by using a sol-gel/spin-coating technique. The presence of the mesoporous structure and titanium oxide species which exist in an isolated and tetrahedrally-coordinated state within the silica framework was observed by XRD and DRUV-vis measurements. The surface wettability on the Ti-MSTFs was also investigated based on the water contact angle measurement. Water contact angles on Ti-MSTFs on quartz and Al alloy substrates were extremely low values of $5^{\circ}$ and $8^{\circ}$ even under dark conditions, respectively, which were much smaller than those on original substrates. These observations indicate that highly hydrophilic surfaces were formed both on quartz and $\mathrm{Al}$ alloy substrates by coating with Ti-MSTFs. It can be interpreted that the capillary condensation due to the mesoporous structure and the presence of isolated titanium oxide species as adsorption sites of water contributed to the appearance of the high hydrophilicity. Furthermore, the irradiation of UV-light led to the decrease in water contact angles on Ti-MSTFs and it was found that Ti-MSTFs exhibited the photoinduced superhydrophilic properties.
\end{abstract}

KEY WORDS: surface hydrophilicity; mesoporous silica thin film; isolated titanium oxide; aluminum alloy.

\section{Introduction}

Wetting properties are underlying and substantially important characteristics related to both physical and chemical fields and their applied ranges extend to all engineering fields. For example, in the fields of a mechanical engineering, wettable surfaces have been investigated for a long period of time from the viewpoint of usage to the junction process. Recently, the control of these properties on solid surfaces and the formation of superhydrophilic surfaces have attracted considerable interests for applications in the microelectronics, thermoelectric conversion elements, sensing devices, self-cleaning, antifogging and antifouling materials. $^{1-5)}$

Oxide semiconductor photocatalysts typified by titanium dioxide $\left(\mathrm{TiO}_{2}\right)$ are one of the materials with potential to control the surface wettability. Since a research on the appearance of superhydrophilic properties on $\mathrm{TiO}_{2}$ thin film under UV-light irradiation, which was named as photoinduced superhydrophilicity, was reported by Shirai et al. in $1974,{ }^{6)}$ several approaches have been proposed to improve this property. ${ }^{7-12)}$ To inhibit the recombination of electron and hole pairs, $\mathrm{TiO}_{2}$ thin film was doped with noble metals.
The decrease in electron density within $\mathrm{TiO}_{2}$ leads to an increase in the hydroxyl group acidity and affects the hydrophilic behavior on the surface. ${ }^{7}$ Moreover, it has been reported that the combination of $\mathrm{SiO}_{2}$ with $\mathrm{TiO}_{2}$ thin films can enhance the photoinduced superhydrophilicity and maintain it for a long time under dark conditions. ${ }^{10,12)}$

As another approach to control the wettability, there is the fabrication of nanostructures into the coating films through nanoprinting, template-based extrusion and chemical etching techniques. ${ }^{13-17)}$ The synthesis of nanostructured materials have been a key technology because of their greatest potentials for improving performance of products such as catalysts, electrode materials and separation membranes. Among them, a mesoporous silica and zeolite are extensively and widely investigated in the fields of host materials, adsorbents and electronic devices. ${ }^{18-23)}$ These porous materials are characterized by the well-ordered structure, large surface area and good thermal stability, and therefore provide the nano-scaled reaction site and the molecular shape selectivity due to their framework topologies. In recent years, novel materials embedded highly dispersed transition metal oxide species into the porous silica framework are found and have received much attention as single- 
site photocatalysts. These materials demonstrated efficient and selective catalytic activities and unique and fascinating surface properties, which cannot be attained with bulk $\mathrm{TiO}_{2}{ }^{24-29)}$ As a promising technique for growing or fixing these nanostructured materials on the substrate, a sol-gel, sputtering and vapor deposition method are used well. ${ }^{1,2,8,10)}$

In the present paper, Ti-containing mesoporous silica thin films (Ti-MSTFs), which include isolated and tetrahedrally-coordinated titanium oxide species in the mesoporous silica framework, were prepared on Al alloy as well as quartz substrates through a sol-gel/spin-coating method and investigated these surface hydrophilic properties by the water contact angle measurement before and after UV-light irradiation. The hydrophilic coating not only on the glass but also various metals used in outward walls of a building might enable to reduce the heat island effect. Al alloy was selected as the coating substrate in our research because it is one of the materials widely used in industry such as architectural materials, ductwork, parts for vehicles, equipments and appointments due to its superior workability, corrosion-resistant characteristic and seawater resistance. Especially, 5000 series of Al alloy is often applied to architectural materials. Although Al alloy is very useful materials as described above, there are few reports converting its surface property into hydrophilic. The design of metal surfaces showing high hydrophilicity would enable practical and industrial-level applications.

\section{Experimental}

\subsection{Chemicals}

Tetraethyl orthotitanate $\left(\left(\mathrm{C}_{2} \mathrm{H}_{5} \mathrm{O}\right)_{4} \mathrm{Ti}\right.$; TEOT $)$ was purchased from Tokyo Kasei Kogyo Co., Ltd. Tetraethyl orthosilicate $\left(\left(\mathrm{C}_{2} \mathrm{H}_{5} \mathrm{O}\right)_{4} \mathrm{Si}\right.$; TEOS $)$ was purchased from Wako Pure Chemical Inc., Ltd. Polyethylene (20) stearyl ether $\left(\mathrm{C}_{18} \mathrm{H}_{37}\left(\mathrm{OCH}_{2} \mathrm{CH}_{2}\right)_{20} \mathrm{OH}\right)$ described as $\mathrm{Brij}^{\circledR} 78$ was purchased from Sigma-Aldrich Co. $5 \mathrm{~N}$ hydrochloric acid $(\mathrm{HCl})$ and ethanol $(\mathrm{EtOH})$ were purchased from Nacalai Tesque, Inc. All chemicals were used as received.

\subsection{Substrates}

Quartz and Al alloy plates were used as coating substrates. Al alloy plate was purchased from HAKUDO Corporation and its GIS NO. was JIS5052. A chemical composition of the employed Al alloy substrate was identified using energy dispersive X-ray spectroscopy (EDS) technique and its elemental ratio was determined to be $\mathrm{Al}: \mathrm{Mg}: \mathrm{Si}: \mathrm{Cr}=97.33: 2.18: 0.26: 0.23$ (wt\%). All plates were cut in the size of $(10 \times 10 \times 1 \mathrm{~mm})$ and rinsed with ethanol before using.

\subsection{Synthesis of Ti-MSTFs on Quartz and Al Alloy Plates}

Ti-MSTFs were prepared on quartz and Al alloy substrates by the sol-gel/spin-coating method in the presence of a structure directing agent (SDA). ${ }^{30)}$ TEOS as silica source, TEOT as titanium oxide source, $\mathrm{Brij}^{\circledR} 78$ as SDA, $\mathrm{HCl}$ and $\mathrm{EtOH}$ were mixed in a teflon bottle, followed by adding of $\mathrm{H}_{2} \mathrm{O}$ while gentle stirring. This sol was further stirred at $293 \mathrm{~K}$ for $20 \mathrm{~min}$. The molar composition of the sol was TEOS+TEOT : $\mathrm{Brij}^{\circledR} 78: \mathrm{HCl}: \mathrm{EtOH}: \mathrm{H}_{2} \mathrm{O}=$

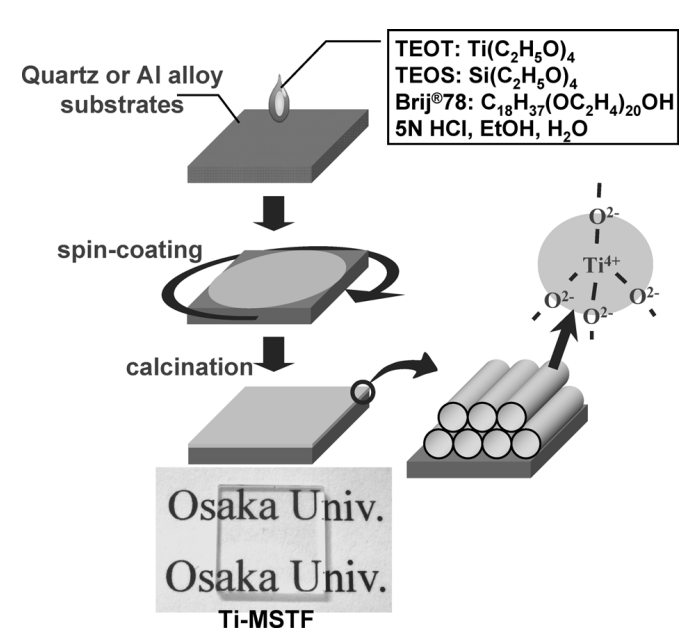

Fig. 1. The schematic illustration of the synthesis procedure and the photographic image of the Ti-MSTF.

$1: 0.05: 0.014: 20: 5(\mathrm{Si}: \mathrm{Ti}=98: 2)$. Thus obtained clear sol was dripped onto quartz and Al alloy substrates, spread evenly and coated at a spinning rate of $4000 \mathrm{rpm}$ for $1 \mathrm{~min}$. After that, for the removal of the SDA, film/plate samples were calcined in air at $723 \mathrm{~K}$ for $5 \mathrm{~h}$ at a heating rate of $2 \mathrm{~K} / \mathrm{min}$. The schematic illustration of the synthesis procedure is shown in Fig. 1. As a sample for the comparison, a Ti-containing silica (Ti-Silica) thin film without the porous structure was also prepared on the quartz substrate by the same method except for using a sol without SDA.

\subsection{Characterizations}

Standard $\theta-2 \theta$ X-ray diffraction (XRD) data were recorded on a Rigaku Mini-flex using $\mathrm{Cu} \mathrm{K} \alpha$ radiation $(\lambda=1.5418 \AA)$ over the range of $1.2-8.0^{\circ}$. Scanning electron microscope (SEM) images were obtained with a JEOL JSM-5600. Diffuse reflectance UV-vis (DRUV-vis) absorption spectra were monitored by a Shimadzu UV-2450 spectrometer at $293 \mathrm{~K}$. The reference sample was $\mathrm{BaSO}_{4}$ and the absorption spectra were obtained by using KubelkaMunk function.

\subsection{Measurement of Water Contact Angle}

The water-repellency of the film/plate surface was checked by the contact angle of pure water $(3 \mu \mathrm{L})$ using a contact angle meter DropMaster 300 of Kyowa Interface Science Co., Ltd. A $10 \mathrm{~mW}$ He-Ne laser, a bandpass filter, a high-resolution $(2000 \times 1312$ pixels $)$ digital camera with a remote controller, a video and an image automatic transmission and processing system were used for the measurement. Because the band-pass filter can cut all other wavelengths except for the laser beam $(632 \mathrm{~nm})$, the reflected light can be removed and high definition drop profiles can be obtained. The film/plate surface was irradiated with UVlight using a $200 \mathrm{~W}$ mercury xenon lamp of San-ei Electric Co., Ltd. at $35 \mathrm{~mW} / \mathrm{cm}^{2}$ for $2 \mathrm{~h}$.

\section{Results and Discussion}

Ti-MSTFs were synthesized on quartz and Al alloy substrates and showed the good adhesion to these substrates. As shown in Fig. 1, the quartz substrate kept its transparency even after the coating of the Ti-MSTF, indicating 


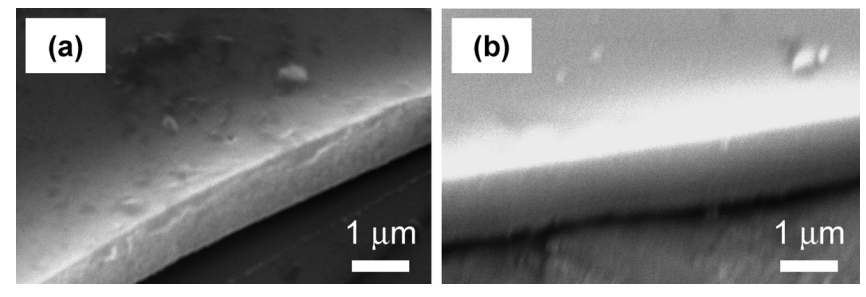

Fig. 2. Cross-section SEM images of Ti-MSTFs on (a) quartz and (b) Al alloy substrates.

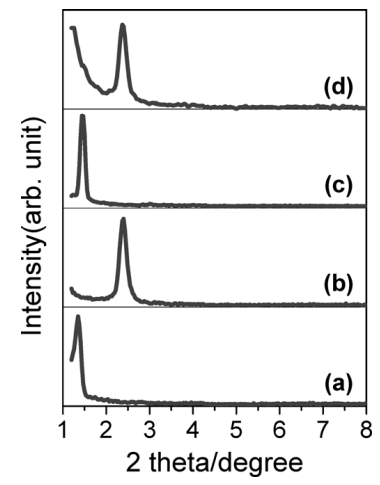

Fig. 3. XRD patterns of Ti-MSTFs on $(a, b)$ quartz and (c, d) Al alloy substrates before $(a, c)$ and after $(b, d)$ calcination.

that the Ti-MSTF is completely transparent and colorless. It can be said that these properties are very useful for practical applications.

Figure 2 shows cross-section SEM images of Ti-MSTFs on quartz and $\mathrm{Al}$ alloy substrates. From these images, mean thicknesses of Ti-MSTFs were determined to be about $1 \mu \mathrm{m}$ and any cracks and abnormal large particles were not observed.

The presence of the porous structure of Ti-MSTFs was confirmed by low-angle XRD measurement. Figure 3 shows diffraction patterns of Ti-MSTFs on quartz and Al alloy substrates before and after calcination. These samples exhibited a single diffraction peak at around $2 \theta=1.5-2.5^{\circ}$, indicating the formation of 2-D hexagonal mesostructure wherein the peak could be directly indexed to be (100) Bragg plane. After calcination, the $d_{100}$ spacing was slightly smaller than that of the sample before calcination. These results suggest that the calcination process causes the formation of the mesoporous structure with their silica framework contractions by the removal of the SDA. On the other hand, in higher angle of XRD patterns, any peaks corresponding to the crystalline titanium dioxide phases were not observed. This indicates that titanium oxide species are highly dispersed within the silica framework.

For the investigation on the state of titanium species in the mesostructured silica framework, DRUV-vis absorption measurement was conducted. Electronic spectroscopy in the UV-vis region is a useful technique to study the electronic state of isolated transition metal ions and aggregated transition metal oxides. Figure 4 shows the DRUV-vis absorption spectra of the Ti-MSTF on the quartz substrate and $\mathrm{TiO}_{2}$ powder (P-25). Absorption band of the Ti-MSTF was observed in the wavelength region of $200-250 \mathrm{~nm}$. This absorption band in the UV-wavelength region is attributed to the ligand-to-metal charge-transfer (LMCT) band from $\mathrm{O}^{2-}$ to $\mathrm{Ti}^{4+}$ ions in a tetrahedrally-coordinated titanium oxide

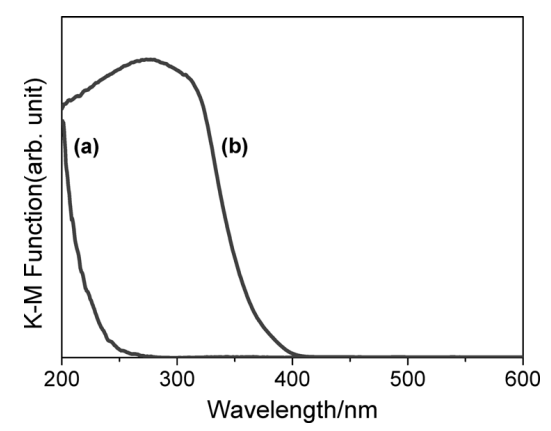

Fig. 4. UV-vis spectra of the (a) Ti-MSTF and (b) $\mathrm{TiO}_{2}$ powder (P-25).

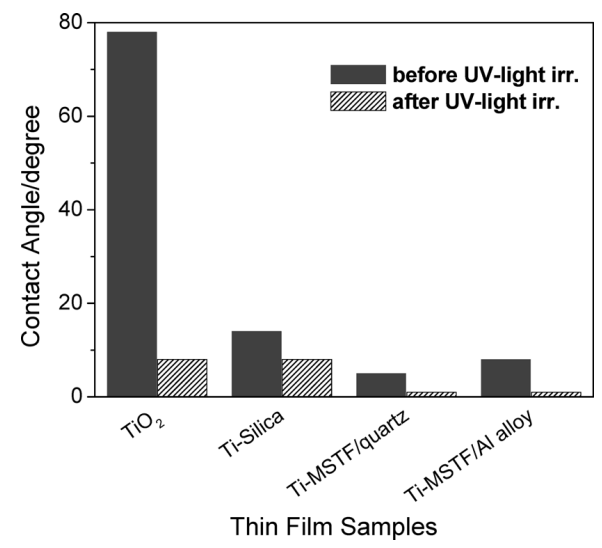

Fig. 5. Water contact angles on various thin film samples before and after UV-light irradiation.

species. ${ }^{22,31-33)}$ Moreover, in the spectrum of the Ti-MSTF, no band was observed in the wavelength region longer than $340 \mathrm{~nm}$ detectable for the $\mathrm{TiO}_{2}$ powder. It was revealed that titanium oxide species within the Ti-MSTF exist in an isolated and tetrahedrally-coordinated state without the formation of aggregated octahedrally-coordinated species.

Surface wettability of Ti-MSTFs on quartz and Al alloy substrates was evaluated by measuring contact angles of water droplets before and after UV-light irradiation. The results of the water contact angle measurement are summarized in Fig. 5. As reference samples, the Ti-Silica thin film prepared without the SDA and $\mathrm{TiO}_{2}$ thin film prepared by the magnetron sputtering deposition method were also investigated. The photographic images of water droplets on these samples are shown in Fig. 6. The water contact angle on the $\mathrm{TiO}_{2}$ thin film before UV-light irradiation was $78^{\circ}$ and it was found that this film showed poor hydrophilicity. In contrast, the Ti-Silica thin film exhibited smaller contact angle, whose value was $14^{\circ}$, indicating that the combination of $\mathrm{TiO}_{2}$ and silica enhanced the surface hydrophilicity. This is because silica moieties contain a large amount of silanol (Si-OH) groups, on which atmospheric water molecules adsorb efficiently. The isolated titanium oxide species in the silica framework also serve as strong adsorbed sites of water attributable to the localization of electrons. Additionally, hydrophilic silica moieties prevent the adsorption of lipophilic oily dusts in the air. In the case of Ti-MSTFs on quartz and $\mathrm{Al}$ alloy substrates which possess the mesoporous structure, water contact angles were $5^{\circ}$ and $8^{\circ}$, respectively, suggesting that they showed highly hydrophilic properties even before UV-light irradiation. These enhance- 


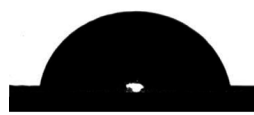

(a)

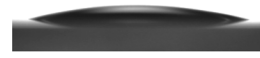

(b)

年

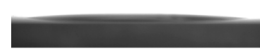

(c)

(d)
(A)

(B)

(C)

(D)
Fig. 6. Photographic images of water droplets on the (a, A) $\mathrm{TiO}_{2}$ thin film, (b, B) Ti-Silica thin film, Ti-MSTF on the (c, C) quartz and (d,D) Al alloy substrates before and after (capital) UV-light irradiation.

ments of the surface hydrophilicity are attributed to the capillary condensation and their high-specific surface areas, which increase the amount of silanol groups in thin film samples, due to their mesoporous structures. From the viewpoint of practical utilization, high hydrophilicity even under dark conditions is very useful. Furthermore, UV-light irradiation induced an additional decrease in water contact angles on Ti-Silica thin film and Ti-MSTFs on two substrates, suggesting that these samples perform the photoinduced superhydrophilicity as similar to that of the $\mathrm{TiO}_{2}$ thin film, whereas a pure MSTF without titanium oxide species exhibited no significant change of water contact angles before and after UV-light irradiation. It can be interpreted that the charge transfer excited state generated from tetrahedrally-coordinated titanium $\mathrm{TiO}_{4}$ species under UV-light irradiation is related to the appearance of superhydrophilic properties. As compared to the Ti-Silica thin film, TiMSTFs showed smaller water contact angles after UV-light irradiation. This observation points out that the formation of the mesoporous structure is conducive to not only the capillary condensation but also the increase of the amount of isolated Ti-sites which exist not within the bulk of the silica framework but on the inner and outer surfaces of the porous structure.

\section{Conclusion}

In summary, transparent Ti-MSTFs were successfully prepared on quartz and $\mathrm{Al}$ alloy substrates using the sol-gel/spin-coating method. XRD and DRUV-vis measurements revealed that Ti-MSTFs possess mesoporous structure and isolated and tetrahedrally-coordinated titanium oxide species in the mesoporous silica framework. These architectures had an influence on the enhancement of the surface hydrophilicity critically, and thereby Ti-MSTFs on quartz and Al alloy substrates exhibited highly hydrophilic properties even under dark conditions. In addition, these film/plate samples demonstrated the photoinduced superhydrophilicity under UV-light irradiation.

\section{Acknowledgement}

This study is financially supported by ISIJ Research Promotion Grant (incl. Ishihara/Asada Grant) and Grants-in-
Aid for Scientific Research (KAKENHI) from Ministry of Education, Culture, Sports, Science and Technology of Japan (No. 21656207). Y. H. expresses his special thanks for Priority Assistance for the Formation of Worldwide Renowned Center of Research-The Global COE Program (Project: Center of Excellence for Advanced Structural and Function Materials Design) from Ministry of Education, Culture, Sports, Science and Technology of Japan.

\section{REFERENCES}

1) Y. Horiuchi, T. Kamegawa, K. Mori, H. Yamashita and N. Nishiyama: e-J. Surf. Sci. Nanotech., 7 (2009), 141.

2) Y. Horiuchi, K. Mori, N. Nishiyama and H. Yamashita: Chem. Lett., 37 (2008), 748.

3) Q. Zhang, F. Xia, T. Sun, W. Song, T. Zhao, M. Liu and L. Jiang: Chem. Commun., (2008), 1199.

4) S. Hu, X. Cao, Y. Song, C. Li, P. Xie and L. Jiang: Chem. Commun., (2008), 2025.

5) J. Lahann, S. Mitragotri, T.-N. Tran, H. Kaido, J. Sundaram, I. S. Choi, S. Hoffer, G. A. Somorjai and R. Langer: Science, 299 (2003), 371.

6) Y. Shirai, K. Ishikawa and G. Miyamoto: J. Soc. Photogr. Sci. Technol. Jpn., 37 (1974), 192.

7) F. Meng and Z. Sun: Appl. Surf. Sci., 255 (2009), 6715.

8) K. R. Denison and C. Boxall: Langmuir, 23 (2007), 4358.

9) N. Sakai, A. Fujishima, T. Watanabe and K. Hashimoto: J. Phys. Chem. B, 105 (2001), 3023.

10) K. Miyashita, S. Kuroda, T. Ubukata, T. Ozawa and H. Kubota: J. Mater. Sci., 36 (2001), 3877.

11) R. Wang, N. Sakai, A. Fujishima, T. Watanabe and K. Hashimoto: $J$. Phys. Chem. B, 103 (1999), 2188.

12) M. Machida, K. Norimoto, T. Watanabe, K. Hashimoto and A. Fujishima: J. Mater. Sci., 34 (1999), 2569.

13) D. Ishii, H. Yabu and M. Shimomura: Chem. Mater, 21 (2009), 1799 .

14) C. Lee, J. Drelich and Y. Yap: Langmuir, 25 (2009), 4853.

15) S. Yang, S. Chen, Y. Tian, C. Feng and L. Chen: Chem. Mater, 20 (2008), 1233.

16) H. S. Lim, D. Kwak, D. Y. Lee, S. G. Lee and K. Cho: J. Am. Chem. Soc., 129 (2007), 4128.

17) L. Feng, Y. Song, J. Zhai, B. Liu, J. Xu, L. Jiang and D. Zhu: Angew. Chem. Int. Ed., 42 (2003), 800.

18) Y. Kuwahara, K. Maki, Y. Matsumura, T. Kamegawa, K. Mori and H. Yamashita: J. Phys. Chem. C, 113 (2009), 1552.

19) Y. Kuwahara, T. Kamegawa, K. Mori and H. Yamashita: Chem. Commun., (2008), 4783.

20) N. Nishiyama, J. Kaihara, Y. Nishiyama, Y. Egashira and K. Ueyama: Langmuir, 23 (2007), 4746.

21) S. Li, Z. Li, D. Medina, C. Lew and Yan: Chem. Mater, 17 (2005), 1851.

22) P. Wu and T. Tatsumi: Catal. Surv. Asia, 8 (2004), 137.

23) A. Corma: Chem. Rev., 97 (1997), 2373.

24) H. Yamashita, K. Mori, S. Shironita and Y. Horiuchi: Catal. Surv. Asia, 12 (2008), 88.

25) K. Mori, Y. Kondo, S. Morimoto and H. Yamashita: J. Phys. Chem. C, 112 (2008), 397.

26) H. Yamashita and K. Mori: Chem. Lett., 36 (2007), 348.

27) H. Yamashita and M. Anpo: Curr. Opin. Solid State Mater. Sci., 7 (2003), 471.

28) K. Ikeue, H. Yamashita, M. Anpo and T. Takewaki: J. Phys. Chem. $B, 105$ (2001), 8350.

29) H. Yamashita, Y. Ichihashi, M. Anpo, M. Hashimoto, C. Louis and M. Che: J. Phys. Chem., 100 (1996), 16041.

30) S.-B. Jung, C.-K. Han and H.-H. Park: Appl. Surf. Sci., 244 (2005), 47.

31) M. E. Raimondi, E. Gianotti, L. Marchese, G. Martra, T. Maschmeyer, J. M. Seddon and S. Coluccia: J. Phys. Chem. B, 104 (2000), 7102.

32) L. Marchese, T. Maschmeyer, E. Gianotti, S. Coluccia and J. M. Thomas: J. Phys. Chem. B, 101 (1997), 8836.

33) W. Zhang, M. Froba, J. Wang, P. T. Tanev, J. Wong and T. J. Pinnavaia: J. Am. Chem. Soc., 118 (1996), 9164. 